\title{
Corrigendum to "Miliary Tuberculosis Presenting with ARDS and Shock: A Case Report and Challenges in Current Management and Diagnosis"
}

\author{
Keevan Singh $\mathbb{D}^{1},{ }^{1}$ Saara Hyatali, ${ }^{2}$ Stanley Giddings, ${ }^{3}$ \\ Kevin Singh, ${ }^{2}$ and Neal Bhagwandass ${ }^{2}{ }^{2}$ \\ ${ }^{1}$ Anaesthesia and Intensive Care Department, San Fernando General Hospital and Department of Clinical Surgical Sciences, \\ University of the West Indies, San Fernando, Trinidad, Trinidad and Tobago \\ ${ }^{2}$ Internal Medicine Department, San Fernando General Hospital, San Fernando, Trinidad and Tobago \\ ${ }^{3}$ Infectious Disease Unit, San Fernando General Hospital and Department of Clinical Medical Sciences, University of the West Indies, \\ San Fernando, Trinidad, Trinidad and Tobago \\ Correspondence should be addressed to Keevan Singh; keevansingh@gmail.com \\ Received 17 February 2018; Accepted 21 February 2018; Published 14 May 2018 \\ Copyright (C) 2018 Keevan Singh et al. This is an open access article distributed under the Creative Commons Attribution License, \\ which permits unrestricted use, distribution, and reproduction in any medium, provided the original work is properly cited.
}

In the article titled "Miliary Tuberculosis Presenting with ARDS and Shock: A Case Report and Challenges in Current Management and Diagnosis" [1], the name of the fifth author was given incorrectly as Neil Bhagwandass. The author's name should have been written as Neal Bhagwandass. The revised authors' list is shown above.

\section{References}

[1] K. Singh, S. Hyatali, S. Giddings, K. Singh, and N. Bhagwandass, "Miliary tuberculosis presenting with ards and shock: a case report and challenges in current management and diagnosis," Case Reports in Critical Care, vol. 2017, Article ID 9287021, 4 pages, 2017. 


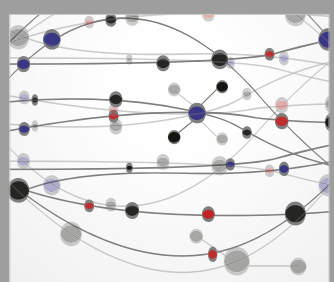

The Scientific World Journal
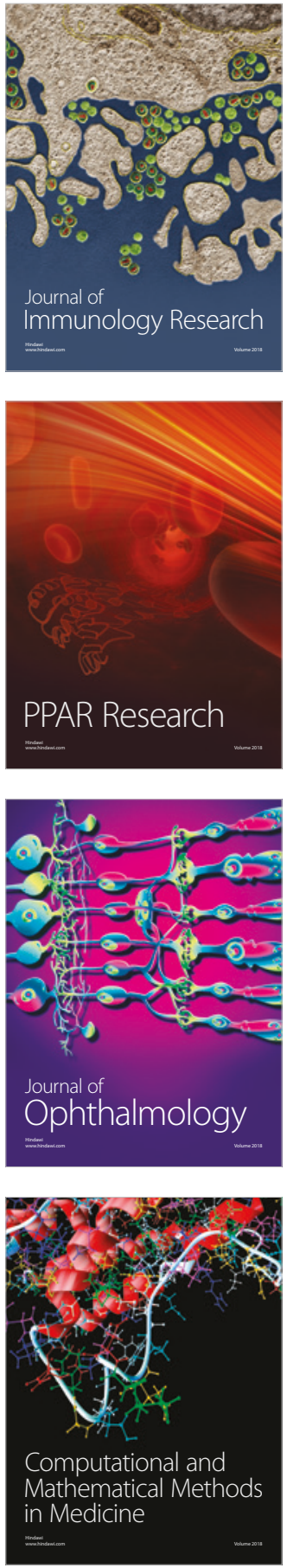

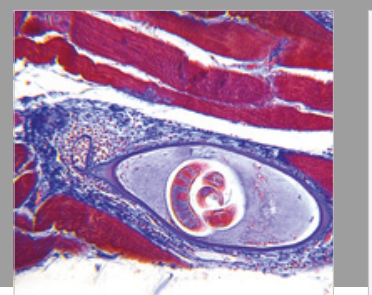

Gastroenterology Research and Practice

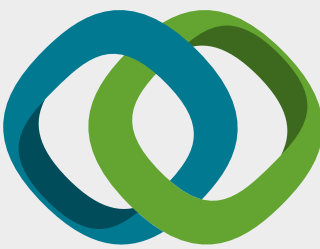

\section{Hindawi}

Submit your manuscripts at

www.hindawi.com
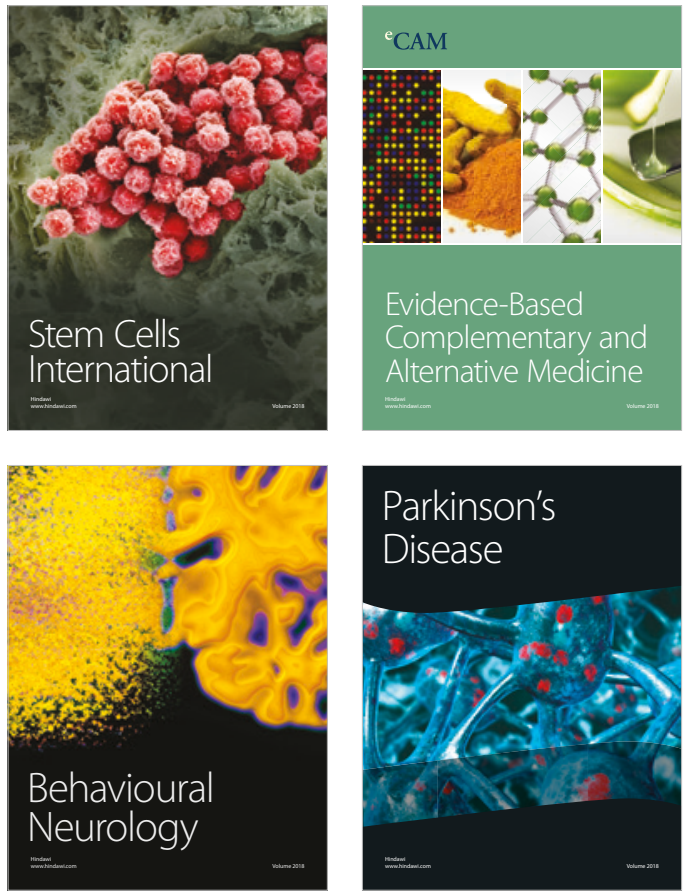

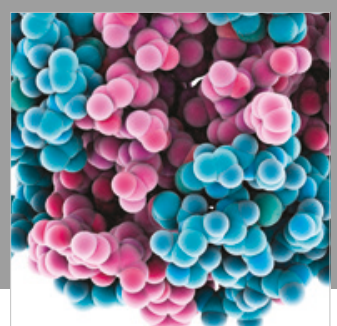

ournal of

Diabetes Research

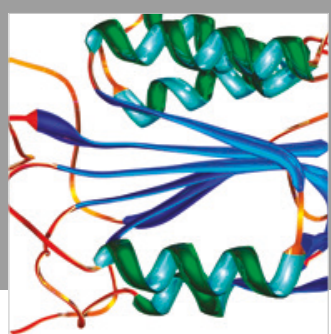

Disease Markers
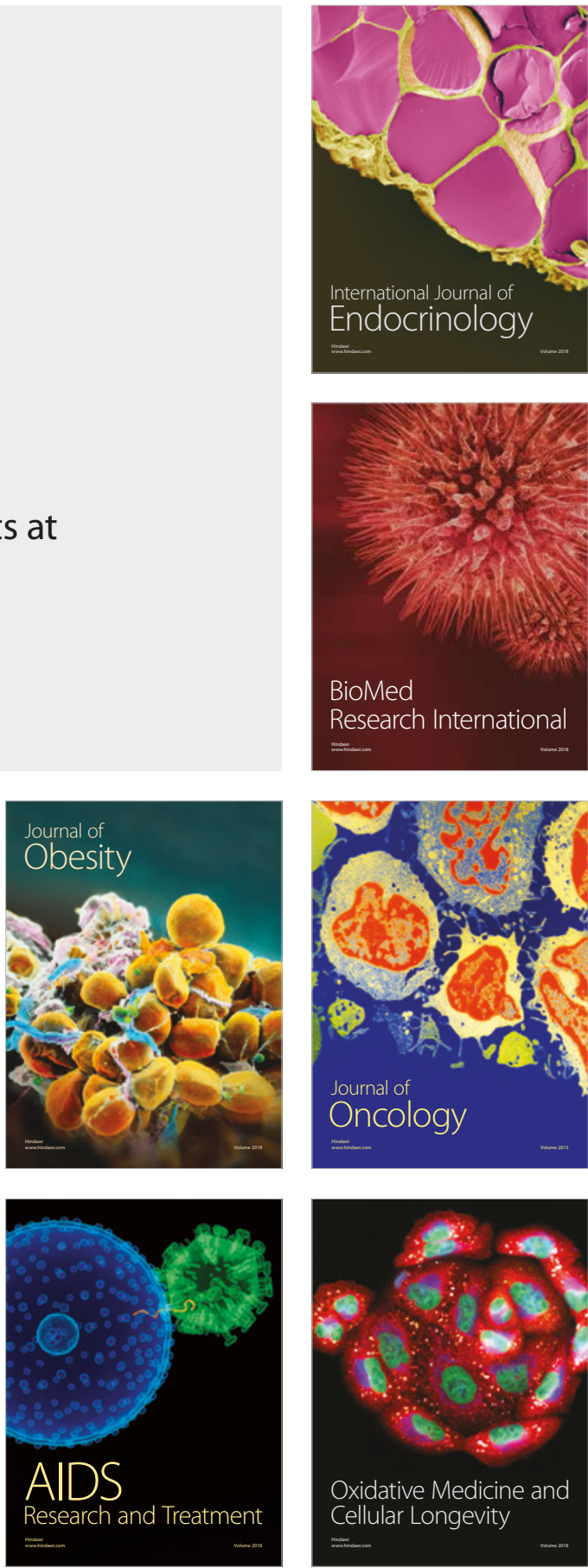